\title{
Implicações do retorno ao trabalho após licença-maternidade na rotina e no trabalho da mulher
}

\author{
Carla Fernandes Garcia, ${ }^{\text {Orcid }} \star$ Juliane Viecili ${ }^{\text {Orcid }}$ \\ Universidade do Sul de Santa Catarina, Palhoça, SC, Brasil
}

\begin{abstract}
Resumo
O aumento da inserção da mulher no mercado de trabalho formal e as mudanças do papel feminino nos séculos XX e XXI, remetem a uma adaptação da mulher a esta realidade social. Muitas vezes, é necessário conciliar funções onde a mulher é desafiada a atender diversas demandas e cumprir expectativas provenientes de cada uma delas, como as funções profissional e materna. Este estudo buscou caracterizar as implicações na relação de mulheres com seu trabalho e rotina pessoal após a licença maternidade. Os dados foram coletados por meio de entrevista semiestruturada aplicadas a mulheres que haviam retornado ao trabalho após a licença maternidade de seu primeiro filho. Dentre os resultados, verificou-se que a maternidade é uma experiência significativa que influencia na rotina e no trabalho da mulher. Verificou-se ainda que as mulheres optam por conciliar os papéis materno e profissional, por perceberem beneficios sociais, cognitivos e emocionais viabilizados pelo trabalho.
\end{abstract}

Palavras-chave: função materna; licença maternidade; trabalho feminino.

\section{Implications of returning to work after maternity leave in routine and in women's work}

\begin{abstract}
The rise of the insertion of the woman in the formal job market an the changes in the female role in the age XX e XXI, remit to a woman adapting to this social reality. It is often necessary to conciliate functions where the woman is challenged to meet various demands and fulfill the expectations from each of them, such as professional and maternal functions. This study sought to characterize the implications on women's relationship with his work and his personal routine on returning to work after maternity leave. The dates have been collected through semi-structured interviews applied to wives which they had returned to work after maternity leave of her first son. Among the results, it was observed that motherhood is a meaningful experience and that influence in the routine and women's work. However also it was found that, for realize social, cognitives and emotional benefits made possibles by the work, women opt for combine both roles.
\end{abstract}

Keywords: maternal function; maternity leave; women's work.

\section{Introdução}

Desde a inserção da mulher no mercado de trabalho formal, inúmeras transformações e desafios foram imputados à realidade feminina. A relação de trabalho remunerado, fora do âmbito doméstico, caracterizou-se como mais um papel na vida da mulher, que historicamente já trazia consigo os papéis legitimados de mãe e de cuidadora de casa, fruto de uma sociedade patriarcal, conforme mencionado por Nascimento e Villas Bôas (2016).

Informações levantadas por Andrade (2016) junto aos Censos Demográficos do IBGE apontam que, em 1950, apenas 13,6\% das mulheres eram economicamente ativas. A partir de então, segundo a autora, a participação das mulheres na População Economicamente Ativa (PEA) vem crescendo significativamente e de forma constante, saltando de 13,6\% em 1950 para 49,9\% em 2010. Acompanhando este movimento de inserção feminina no mercado de trabalho brasileiro ao longo das décadas, algumas legislações foram elaboradas visando oferecer amparo e proteção às mulheres na realização de suas atividades. No século XX, no ano de 1943, o presidente Getúlio Vargas criou a Consolidação das Leis do Trabalho (BRASIL, 1943) - CLT - unificando toda a legislação relativa ao trabalho no país. Com o passar do

\footnotetext{
^Endereço para correspondência: Universidade do Sul de Santa Catarina, Departamento de Ciências Humanas, Ciências da Educação, Letras e Artes. Av. Pedra Branca, 25 - Cidade Universitária Pedra Branca - Palhoça, Santa Catarina, SC - Brasil.CEP: 88132000.E-mail: carlapsc@yahoo.com.br, jviecili@gmail.com
}

tempo, a CLT foi sendo atualizada de acordo com demandas dos trabalhadores em geral, resultando no conjunto de leis em vigor neste início do século XXI, que dispõem, entre outros, de direitos específicos à proteção da mulher, como por exemplo, o direito à licença maternidade de 120 dias, sem prejuízo no salário da trabalhadora, previsto no artigo 392 da presente lei. O artigo 391 garante estabilidade à gestante desde a confirmação da gravidez até cinco meses após o parto. A CLT prevê ainda, pausas para a amamentação no Artigo 396, onde a mulher tem direito a duas pausas de meia hora durante a sua jornada de trabalho, para amamentar seu bebê até que ele complete seis meses de idade. $\mathrm{O}$ artigo 389 , em seu parágrafo $1^{\circ}$ e $2^{\circ}$ assegura que a mulher tenha um local para deixar o filho no período de amamentação, que vai até os seis meses conforme o artigo anteriormente citado. Em virtude da dificuldade dos empregadores em disponibilizar um local adequado para que as crianças sejam mantidas, foi criada a Portaria 3.296/1986, alterada pela Portaria 670/97, em substituição ao que preconizam os parágrafos $1^{\circ}$ e $2^{\circ}$ do artigo 389. Esta portaria diz que o empregador poderá adotar o sistema de reembolso-creche quando tiver dificuldade de dispor do local para que as mães deixem os bebês dentro da própria empresa. $\mathrm{O}$ valor do reembolso creche oferecido, deverá ser acordado em convenção coletiva, entre o sindicato dos trabalhadores e a empresa ou sindicato dos empregadores. 
Ao se contrastar a legislação em vigor com a realidade do século XXI, um questionamento pode ser suscitado: a legislação existente é suficiente para atender as demandas sociais e emocionais existentes em situação de gestação e meses subsequentes ao parto, garantindo os direitos constitucionais tanto das crianças como de suas mães? Discutir a relação entre o trabalho feminino e a maternidade torna-se importante para instrumentalizar os diversos atores sociais - trabalhadores, organizações e sindicatos - a buscar o cumprimento da legislação existente e promover melhorias e adequações às novas realidades, para que as trabalhadoras possam ter protegidos o acesso e a permanência no mercado de trabalho.

Salanova, Gracia e Peiró (1996 apud SANTOS, 2006) apontam diversos benefícios que o trabalho formal e remunerado pode proporcionar aos indivíduos que o exercem: proporcionar sentido à vida, realização pessoal e melhora na autoestima; conquista de status e prestígio social; a constituição da identidade pessoal; o ganho econômico para sobrevivência, aquisição de bens de consumo e independência; possibilitar contatos sociais e maior rede de relacionamento; fornecer um referencial quanto à estruturação do tempo (dia, mês e ano), estabelecido através da rotina; sentimento de utilidade e prestação de serviço à sociedade; fonte de oportunidades para o desenvolvimento de habilidades; possui também a função de transmissão de normas, crenças e expectativas sociais; função de proporcionar poder entre os indivíduos e, por fim, a função de proporcionar comodidade e conforto. Codo (2006) apresenta os impactos do trabalho no sujeito de forma triangular, relacionando o sujeito, a atividade realizada e o significado gerado. Para este autor, o trabalho formal vai além da simples venda da força braçal (ou intelectual) como mercadoria, já que envolve uma relação de significação para o sujeito que realiza a atividade. Ou seja, transforma-se a natureza através da atividade realizada com a força de trabalho, e se é transformado pela atividade realizada. Assim, evidencia-se que as mulheres inseridas no mercado de trabalho formal e regulamentado, usufruindo de todos os direitos previstos, passam a ter acesso não somente aos ganhos financeiros, mas também à oportunidade de construir sua subjetividade permeada por todos os benefícios que o trabalho lhes proporciona.

Para Alves (2009), o aumento da participação da mulher no mercado de trabalho, foi um dos fatores que promoveu as mais significativas transformações na organização da sociedade. As mulheres conquistaram um novo status sobre o seu papel social e em decorrência disto assumiram novas funções. Para Nascimento e Villas Bôas (2016), as transformações culturais que colocaram a mulher no mercado de trabalho, aumentaram sobremaneira as suas tarefas, tanto domésticas, como de cuidado com a prole, quanto de trabalho formal, e assim, a mulher ganhou uma nova posição revestida de responsabilidades individuais, familiares e sociais, que lhe impuseram mudanças de comportamento. Profissionalização, maternidade e cuidados do lar são algumas das atribuições femininas comuns na atualidade, e que juntas exigem muito dos atributos físicos e psíquicos das mulheres (CAVALCANTI; BAÍA, 2017).

Vinhas (2009) aponta que, mesmo em meio a mudanças, a sociedade continua esperando que a mulher, mantenha a família, a casa e os filhos no âmago de suas vidas. Existe maior liberdade, aceitação social e até estímulo para que a mulher assuma novos papéis, dentre eles o do trabalho formal, mas ainda cobra-se que ela desempenhe os papéis arraigados no imaginário social de mantenedora do lar, esposa e mãe. Cavalcanti e Baía (2017) mencionam que os meios de comunicação em massa continuam perpetuando a imagem da mulher perfeita, como sendo as máximas e únicas responsáveis pelo cuidado da casa e dos filhos. Rocha-Coutinho (2005) afirma que as mulheres têm sido educadas e encorajadas a buscar uma inserção profissional equiparada à masculina, valorizando seu potencial e independência, entretanto, elas ainda precisam enfrentar o dilema de administrar as necessidades da carreira, do lar e da família, acentuadas na ocasião da maternidade. Nesse contexto, mesmo com as alterações no contexto social, ainda compete à mulher os cuidados com os filho e a casa.

Embora seja crescente a participação da mulher no mercado de trabalho, Nascimento e Villas Bôas (2016) afirmam que a discriminação das mulheres no mercado de trabalho brasileiro ainda é alta, uma vez que enfrentam dificuldades não apenas para ingressarem no mercado de trabalho como também recebem salários menores do que os homens. Não obstante, estas desigualdades impulsionam a busca por qualificação, destacando-se neste sentido que atualmente há mais mulheres do que homens com formação superior (ORGANIZAÇÃO INTERNACIONAL DO TRABALHO [OIT], 2016). Corroborando a condição de desigualdade das mulheres no mercado de trabalho, Godoy et al. (2011) afirmam que as mulheres empregadas formalmente acabam ocupando, em sua maioria, posições de menor prestígio e sofrendo discriminação na admissão, promoção e qualificação profissional. O Relatório da OIT (2010) apresenta sinais de progresso em termos de igualdade de gênero nos últimos 15 anos que antecedem o relatório, mas destaca que ainda permanece uma grande diferença entre homens e mulheres quanto às oportunidades de trabalho e à qualidade do emprego. O que estaria por detrás desta realidade? Guimarães (2012) relaciona este cenário às barreiras culturais ainda presentes na sociedade, onde existe divisão sexual do trabalho, atribuindo às mulheres funções ligadas ao cuidado, à alimentação, à higiene e à organização. De acordo com Godoy et al. (2011) e Nascimento e Villas Bôas (2016), a inserção profissional feminina também é influenciada pela visão dos empregadores de que as mulheres aumentam as despesas organizacionais por terem a predisposição biológica para gerar um filho e, com isso, usufruir de direitos como a licença maternidade remunerada, pausa para a amamentação, auxílio creche e estabilidade no emprego previstos na legislação. Além disso, após o período da licença, as mulheres retornam ao trabalho tendo uma criança muito pequena (em torno de quatro meses), que em tese aumenta 
sua responsabilidade nos cuidados maternos e com o lar, podendo comprometer seu desempenho no trabalho. De fato, o papel materno exige tal dedicação e comprometimento que modificam sobremaneira a realidade da mulher. Ainda assim muitas mulheres, ao tornarem-se mães, mantém seu vínculo empregatício e voltam ao mercado de trabalho logo após a licença.

Diversos estudos têm sido produzidos levando em conta a relação entre o trabalho feminino e o processo da maternidade. Krause (2017) realizou um estudo com 49 servidoras públicas, a fim de identificar a realidade do retorno ao trabalho após a licença maternidade, demonstrando que as mulheres apresentam sentimento de vulnerabilidade, e 70\% delas demonstraram possuir sentimentos negativos relacionados ao trabalho.

Fabbro e Heloani (2010) realizaram uma pesquisa na qual objetivaram identificar a relação entre o trabalho de docência universitária e o nascimento do primeiro filho. Foram entrevistadas cinco professoras de uma Universidade Pública de São Paulo que já haviam retornado ao trabalho após o nascimento do bebê. Os resultados da pesquisa permitiram demonstrar a coexistência de dois papéis na identidade das mulheres: o clássico de mãe e esposa e os papéis mais recentes que envolvem o trabalho formal, o reconhecimento e a construção de uma carreira de prestígio. Porém, o conhecimento produzido pelos autores permite perceber que a vivência do papel materno influencia na carreira das mulheres de forma bastante significativa, a ponto de fazer com que repensem a continuidade e o valor profissional que vinham exercendo, antes tão expressivo e significativo.

No estudo de Vanalli e Barham (2012), foram entrevistadas 40 professoras de todos os níveis (infantil, fundamental e médio) da rede pública de educação, com filhos de até dois anos, com o objetivo de investigar as vivências e as percepções destas mulheres em relação ao seu retorno ao trabalho após a licença maternidade. Contudo, a pesquisa das autoras limitou-se a estudar a percepção das entrevistadas no que tange ao relacionamento com o cônjuge, envolvimento familiar do casal e a presença da rede de apoio que auxiliam nas demandas domésticas e nos cuidados com a criança.

Também no contexto dos dilemas enfrentados pelas mulheres que passam a desempenhar as funções materna e profissional, pesquisas realizadas por Rocha-Coutinho (2005) e outros estudos identificados pela autora (a saber: ROCHA-COUTINHO, 2001, 2003a, 2003b; HARRIS, 1979; HOFFNUNG, 1992, 1995) apontam para o fato de que tanto homens como mulheres ainda trazem a crença de que a provisão financeira da família é de responsabilidade do homem, e os filhos e trabalhos domésticos são de responsabilidade da mulher. Isto impacta em que, não obstante realizarem a mesma carga-horária de trabalho formal fora do âmbito doméstico, as mulheres ainda dedicam mais tempo às atividades domésticas do que seus companheiros. Este fato foi evidenciado também nas pesquisas realizada por Cooper e Lewis (2000, apud VANALLI; BARHAM, 2012), Jablonsky (2003, 2010), Rapoport e Picinini (2006), e no relatório da Organização Internacio- nal do Trabalho (2016) que evidenciam que as mulheres, mesmo quando estão empregadas, realizam 2,5 vezes mais tarefas domésticas e de cuidados do que os homens.

A desigualdade no compartilhamento das tarefas domésticas, no cuidado para com os filhos, na ascensão profissional e socioeconômica e na remuneração financeira pode contribuir para que exista um sentimento de insatisfação nestas mulheres. Além disso, restringe a possibilidade de a mulher aumentar o número de horas dedicadas à busca por formação acadêmica ou especialização técnica. Rodrigues e Sapucaia (2016) ilustram esta realidade, afirmando figuradamente que a cada vez que uma mulher gasta uma hora cuidando dos filhos, fazendo comida ou lavando roupas, ela se afasta ainda mais da potencialidade de absorver papéis não domésticos, tanto profissional como politicamente.

Diante dos desafios dos papéis assumidos pelas mulheres diante das conjecturas impostas pelas condições de trabalho na sociedade, alguns questionamentos são suscitados: Quais os impactos emocionais enfrentados por mulheres ao retornarem ao trabalho após o nascimento de um filho? Como equilibrar as exigências do papel materno com o profissional? Com o objetivo de responder estes questionamentos, nesta pesquisa buscou-se verificar a relação das mulheres com seu trabalho e com sua nova rotina ao vivenciarem a maternidade pela primeira vez e retornar às atividades de trabalho, após o afastamento de licença-maternidade.

\section{Método}

\subsection{Participantes}

Participaram da pesquisa seis mulheres trabalhadoras que retornaram da licença maternidade há em média seis meses, casadas ou em união estável e mães do primeiro filho. Como critério de inclusão das participantes, foi considerado ser maior de idade, ser casada ou possuir um companheiro estável, ser mãe do primeiro filho, ter retornado ao trabalho após afastamento por licença-maternidade há pelo menos dois meses e no máximo há nove meses, estar empregada em um emprego formal desde antes da gestação, e continuar no mesmo emprego após ela.

As participantes foram selecionadas por meio da técnica chamada "bola de neve" na qual, segundo Patton (1990 apud JIMENEZ, 2001, p. 57), deve-se identificar um sujeito que se adéque aos critérios da pesquisa, e a este solicita-se que indique outro sujeito na mesma condição e assim sucessivamente. Após identificar as participantes em potencial para esta pesquisa, realizou-se um primeiro contato telefônico, onde os objetivos da pesquisa foram apresentados, e foi verificado o interesse e disponibilidade em participar do estudo. Após o aceite, um segundo contato telefônico foi efetivado para agendar dia, horário e local para realização da coleta de dados.

As seis participantes receberam os seguintes nomes fictícios: Alice, Beatriz, Cláudia, Daniele, Eduarda e Flávia. Os nomes escolhidos foram aleatórios, entretanto adotou-se ordem alfabética de acordo com a ordem em que foram entrevistadas, ou seja, a primeira participante 
a ser entrevistada recebeu o nome de Alice, a segunda participante entrevistada foi nomeada como Beatriz, e assim sucessivamente.

Alice tem 26 anos, possui o ensino superior completo, e trabalha como Assistente Administrativo. Está casada há 2 anos e 6 meses, teve 4 meses de licença maternidade e retornou ao trabalho há 8 meses da data da coleta de dados. Sua gravidez foi planejada, sendo que ela é mãe de uma menina. Durante a semana a criança fica em uma escola de educação infantil em tempo integral, para que Alice possa trabalhar.

Beatriz, tem 25 anos, possui o ensino médio incompleto e é vendedora. Está casada há 2 anos, teve 4 meses de licença maternidade e retornou ao trabalho há 5 meses. A gravidez de Beatriz foi planejada, e ela é mãe de um menino. Atualmente para Beatriz poder trabalhar, sua mãe é quem cuida do bebê.

Cláudia possui 37 anos, é casada há 1 ano e 11 meses e mãe de um menino, fruto de uma gravidez planejada e após um aborto espontâneo. Cláudia teve quatro meses de licença-maternidade e retornou ao trabalho há 5 meses. Possui ensino superior completo com especialização e trabalha como secretária. Cláudia deixa seu bebê numa escola de educação infantil em tempo integral para poder trabalhar.

Daniele possui 29 anos, é bibliotecária e possui o ensino superior completo. Retornou ao trabalho há 5 meses da coleta de dados, e teve 6 meses de licença maternidade. Daniele é casada há 9 anos e é mãe de uma menina, que fica numa escola de educação infantil para que possa trabalhar.

Eduarda possui 27 anos, é assistente administrativo e retornou ao trabalho há 6 meses, tendo uma licença maternidade de 5 meses. Eduarda é casada há três anos, e é mãe de um menino, fruto de uma gravidez planejada. Atualmente sua mãe e sua sogra revezam-se no cuidado com o bebê, para que ela possa trabalhar.

Flávia é casada há seis anos, possui 30 anos, é professora e mãe de uma menina. Flávia teve três meses de licença maternidade, e voltou a trabalhar com uma carga-horária menor no primeiro mês do retorno. Após completar os quatro meses de licença, Flávia voltou a trabalhar normalmente. A gravidez de Flávia foi planejada e ocorreu após dois abortos. Durante seu expediente, Flávia deixa a criança na própria escola onde trabalha.

\subsection{Instrumento de coleta de dados}

Para embasar a discussão acerca do trabalho feminino após a vivência da maternidade, realizou-se uma entrevista semiestruturada com 30 questões abertas, elaboradas com base nos eixos de análise criados a partir das variáveis que compõe o fenômeno em estudo. As perguntas contempladas no roteiro, abordaram questões relacionadas à rotina pessoal das participantes (5 questões), ao cuidado pessoal (6 questões), ao relacionamento conjugal (5 questões), a experiência da maternidade e ao filho (7 questões) e às relações de trabalho (6 questões), além de uma questão aberta para que as mulheres pudessem complementar com alguma informação que não houvesse sido contemplada nas questões anteriores.

\subsection{Procedimento de coleta de dados}

As entrevistas foram agendadas conforme a disponibilidade das entrevistadas, dando preferência por entrevistá-las no local de trabalho em horário comercial. Os dados foram coletados no local de trabalho de cinco participantes. Os dados da sexta participante foram coletados em um salão comunitário próximo à casa da participante. Buscou-se realizar a coleta de dados em locais tranquilos, livre de ruídos e interrupções.

No momento da coleta de dados foi explicado o Termo de Consentimento Livre e Esclarecido, assegurando o sigilo das informações, e coletada a assinatura no mesmo. Todas as participantes concordaram com as informações expostas, autorizaram a gravação do áudio das entrevistas, e assinaram o Termo de Consentimento Livre e Esclarecido. Após, deu-se início às entrevistas, que tiveram uma média de duração de vinte e oito minutos.

\subsection{Procedimento de organização e tratamento dos dados}

Realizadas todas as entrevistas, procedeu-se com a transcrição literal das mesmas. Em seguida, as entrevistas foram organizadas em um quadro de análise, de acordo com os eixos de análise definidos a priori, e tratadas a partir da análise de conteúdo baseada na proposta de Laurence Bardin (2011), onde o pesquisador deve realizar um esforço analítico que vai além do discurso verbal, avaliando também o que está por detrás das falas, permitindo a interpretação e a inferência. Seguindo o método da análise de conteúdo de Bardin (2011), foram criadas a posteriori as categorias de respostas apresentadas pelas participantes. Todas as categorias apresentadas foram registradas em uma tabela eletrônica, vinculadas a seu eixo de análise. A partir disto, selecionaram-se os dados relativos a dois eixos de análise que são apresentados neste artigo, a saber: a) implicações do retorno ao trabalho após a licença maternidade na rotina de vida e b) implicações do retorno ao trabalho após a licença maternidade nas relações de trabalho das mulheres. Durante as entrevistas, foi investigada a percepção destas mulheres antes do período de gravidez, após o parto, durante a licença-maternidade, e após o retorno ao trabalho, em cada eixo de análise. Desta forma, foi possível avaliar as mudanças e implicações que o retorno ao trabalho proporcionou para essas mulheres.

\section{Resultados}

Após transcrição da entrevista e análise dos dados encontrados, optou-se por apresentar, no presente momento, os eixos de análise relacionados às implicações do retorno ao trabalho na rotina e no trabalho da mulher. Verificou-se que as principais mudanças de rotina, apontadas por cinco das seis mulheres entrevistadas, foram o cansaço físico e o aumento das preocupações.

O cansaço físico esteve relacionado com o pouco tempo para realizar as tarefas domésticas, apontado por três entrevistadas. $\mathrm{O}$ nascimento de um bebê acrescenta mais uma função na vida da mulher, aumentando o volume de tarefas domésticas, conforme já apontado por Vanalli e Barham (2012) e ilustrado pela fala de Beatriz: 
Eu estou no meu serviço o dia inteiro [...] Então querendo ou não tu já está cansada, já está exausta do teu dia a dia, o teu dia foi cansativo, tu já chegou em casa, aí vem janta, vem cuidar de filho, dar banho de filho, tomar um banho, então a rotina muda muito a partir do momento em que tu trabalha porque tu tem bem menos tempo do que quando ele nasceu, pra fazer tudo. Sem falar nas tuas atividades domésticas né? Que aumenta muito mais as tuas atividades de casa, porque um bebê exige muito de ti em casa.

Por terem que conciliar as atividades relacionadas ao cuidado com o filho, as tarefas do lar, cuidado pessoal e o relacionamento com o esposo, com o pouco tempo que se encontram em casa, considerando que exercem uma carga-horária integral em seus empregos, as mulheres demonstraram vivenciar um desgaste físico. A fala de Daniele demonstra esta realidade: "Eu estou muito cansada, porque eu tenho que buscar ela na creche, chegar em casa, dar banho, dar mamadeira, cuidar da casa, organizar uma janta. A noite ela ainda não dorme a noite toda, ela acorda duas, três vezes a noite, e eu acordo pra atender ela". Tal fato remete à necessidade de realizar um ajuste em suas rotinas, conforme relatado por Eduarda: "Agora eu me sinto mais cansada. Porque é dificil dar conta de casa, trabalho, marido, e filho. Então eu estou começando a fazer uma nova rotina, tentando organizar, ter meus horários."

As seis participantes afirmaram que as tarefas domésticas e os cuidados para com o bebê são de sua responsabilidade, cabendo ao esposo prestar auxílio quando solicitado. O mesmo foi apontado também por Jablonsky (2010) e Vanalli e Baham (2012) como sendo o que acontece na maioria das famílias. Desta forma, as mulheres participantes realizam uma carga horária semanal maior em atividades domésticas do que seus companheiros, o que gera uma sobrecarga de atividades para elas. As falas de Cláudia e Flávia ilustram esta realidade. Cláudia: "Quando a gente chega é aquela coisa, né? Tem bastante coisa pra dar conta, até pro outro dia. Então eu acabo me dividindo em duas né. Em três... Pra fazer tudo. Porque o [esposo] não tem bem jeito, então eu já prefiro fazer o que tem. Mas se pedir ele até faz o que pedir". Flávia: "Normalmente eu tomo a frente. Sempre foi assim, ainda mais agora né? Com as coisinhas dela pra fazer, normalmente eu faço mais as coisas, e ele fica assim com ela, distraindo, daí coloca pra ver tevê, brinca com ela, enquanto eu ajeito." Dados publicados pela Organização Internacional do Trabalho (2016) evidenciou que as mulheres realizam 2,5 vezes mais tarefas domésticas e de cuidados do que os homens. Esta realidade está atrelada à histórica divisão sexual das demandas familiares, onde a mulher era responsável pelas demandas do lar e o homem, pelo sustento financeiro da família. Ao encontro disto, Noor (2002 apud LINDO et al, 2007) afirma que, em famílias que possuem filhos pequenos, as mulheres exercem cerca de 90 horas de trabalho por semana, somando-se as horas de atividade empregatícia formal e as horas em atividades domésticas, enquanto os homens, companheiros dessas mulheres, exercem cerca de 70 horas somando as mesmas atividades. Isso representa uma diferença de quase três horas diárias em atividades de trabalho - sejam estas em trabalho formal ou doméstico - por dia. Estas horas a mais, realizadas pelas mulheres, implica que estas abram mão de outros interesses ou outras atividades, para darem conta de toda a demanda, gerando cansaço, sobrecarga e desgaste físico e emocional, conforme a fala de Cláudia:

E a minha vida, os meu hobbies, as minhas atividades que eu gostava, que eu fazia, cessaram totalmente. Eu me dedico exclusivamente a ele [filho]. [...] Não que eu não me cuide, mas eu não sou mais a prioridade. Falta tempo pra muita coisa que tá na minha responsabilidade, a vida é corrida. Então é assim, o tempo que me sobra, é dele.

No entanto, Charraz (2017) afirma que ao longo dos anos, esta realidade está se modificado, de maneira que os homens estão ampliando seu envolvimento na esfera privada, da família, proporcionalmente a ampliação do envolvimento da mulher no mercado de trabalho, embora essa inserção masculina na esfera doméstica ainda seja incipiente.

Soma-se à carga de trabalho realizada pela mulher, o impacto emocional gerado pelo afastamento do bebê na ocasião do retorno ao trabalho, que pode repercutir diretamente na sua rotina, bem como em suas relações de trabalho. Krause (2017) menciona que o retorno ao trabalho é marcado por arranjos e reorganizações que costumam promover cansaço, estresse, insegurança, culpa e ansiedade, exigindo um investimento emocional amplo para voltar ao equilíbrio. De fato, esta assertiva evidenciou-se na fala das mulheres entrevistada. Eduarda afirma:

Isso me faz me sentir mais culpada ainda, por estar deixando ele, por não estar lá, não estar junto com ele, não estar vivendo tudo aquilo. Porque todo dia tem uma coisinha nova. Então vem esse sentimento de culpa, e ainda está. Mas no começo, eu tinha quase certeza que eu ia pedir demissão e ia ficar em casa com ele, porque eu tinha um sentimento de culpa, de que eu estava abandonando ele, que eu botei no mundo pros outros criarem.

Vanalli e Barham (2012) já destacam informação semelhante, ao afirmarem que, com o retorno ao trabalho, as famílias precisam se organizar para dividir o cuidado com o filho com outras pessoas ou instituições, o que implica em sentimentos de incertezas e angústia para as mulheres. De fato, quatro participantes afirmaram que o retorno ao trabalho após nascimento do bebê impôs a elas um aumento de preocupações. Entende-se que o nascimento de um bebê naturalmente impõe um aumento de preocupações para seus cuidadores, especialmente quando se trata do primeiro filho. No entanto, as mulheres, ao retornarem ao seu trabalho, acabam afastadas em grande parte do dia de seus bebês e precisam delegar a outros o cuidado com a criança. Isso significa abrir mão do controle intensivo sobre o bebê que foi de sua responsabilidade durante a licença maternidade, período que, em tese, foi dedicado a isto, ressaltando ainda mais o sentimento de preocupação em relação ao bem estar de seus filhos, conforme se evidencia na fala de Beatriz: " $E$ a minha cabeça na maioria das vezes tá mais nele do que 
aqui na empresa sabe? Então eu ligo de manhã, eu ligo meio dia, eu ligo a noite. Porque eu quero saber se ele tá bem, se ele tá com tosse, se ele comeu".

Referente ao segundo eixo de análise, relacionado às mudanças na relação com o trabalho após a licença-maternidade, uma das principais mudanças apontadas pelas mulheres entrevistadas é a percepção de mudança no rendimento no trabalho, relatada por cinco das seis mulheres. Verificou-se que combinação entre o cansaço físico apontado pelas mulheres, a preocupação com o bebê e a necessidade de ausentar-se do trabalho interferem no desempenho das mulheres que retornam ao trabalho após a licença maternidade, diminuindo-o. Tal dado foi também encontrado Krause (2017) que, em seu estudo com 49 servidoras públicas, identificou que a maioria delas percebeu uma queda no seu desempenho profissional. A percepção da diminuição no desempenho profissional, em alguns casos trás um descontentamento para a mulher associado a um sentimento de insegurança, conforme se verifica na fala de Daniele:

Essa questão profissional eu vejo que eu fico devendo. Eu me sinto mal de não estar rendendo bem, de sair uma vez por mês para fazer a consulta médica dela e estar faltando aqui. Então, além do meu rendimento já não ser o mesmo, eu acabo faltando muito por causa dela. Então isso que me incomoda como profissional. Antes não, antes eu não tinha ninguém pra me atrapalhar, eu nunca gostei de faltar.

A fala de Daniele apresenta o quanto as demandas com o bebê impactam na qualidade do seu trabalho e demonstra insatisfação com a queda no rendimento profissional. Tal situação pode colocar a mulher numa posição estressante, de constante de autocobranças e culpabilização, conforme ilustrado anteriormente, na fala de Daniele. A partir da fala das outras participantes, também foi possível observar um sentimento ambíguo de insatisfação nas trabalhadoras. O retorno da mãe ao trabalho formal implica em sentimentos de "falta" nos cuidados com o filho e, ao mesmo tempo, a trabalhadora que se torna mãe e continua no mercado de trabalho sente que sua dedicação ao trabalho fica comprometida. A mulher se vê dividida entre dois universos diferentes e que demandam empenho. A fala de Alice ilustra:

É que é assim, nem no trabalho a gente se desliga da família e às vezes nem na família a gente se desliga do trabalho né. A nossa cabeça é incrível, porque é muita coisa. Aí tem que cuidar dela, dar comida, aí tem o marido, daí tem mais aquela coisa lá no trabalho que a gente não resolveu. Então a gente vive sempre pensando em tudo isso, porque são as nossas responsabilidades né?

A maternidade muitas vezes é encarada pelas mulheres, como um compromisso social que assumem, conforme discute Schlickmann (2010). Socialmente, estabelece-se que os pais devem prover alimentação, segurança e conforto para seus filhos. Assim, os rendimentos financeiros proporcionados pelo trabalho à mulher, permitem que elas possam cumprir sua parte nas exigências deste compromisso social adquirido com a maternidade. Por conta disso, verifica-se que o emprego passa a ter maior importância para algumas mulheres. A fala de Alice ilustra o novo sentido que o trabalho adquire: "Antes eu me sentia uma jovem que podia trocar de emprego, $e$ hoje eu me sinto uma adulta que tem responsabilidades e tem que cumprir com essas responsabilidades." $\mathrm{O}$ emprego atual passa a ter maior importância, fazendo com que mulheres trabalhadoras que se tornam mães valorizem a estabilidade e a segurança financeira que o trabalho lhe proporciona e que lhes permite suprir as novas demandas e necessidades da família. Isso pode justificar o fato de que a percepção da queda do rendimento no trabalho as deixa incomodadas. Passaria o trabalho a ter um novo significado para elas? Se antes o trabalho era visto como um meio de obter a satisfação e o crescimento pessoal, após o nascimento de um filho parece que o trabalho passa a ser visto como um meio de garantir a segurança financeira familiar. Assim, maternidade e as novas demandas sociais advindas do nascimento de um bebê, podem gerar um maior comprometimento da mulher para com seu trabalho - o que se torna positivo para a empresa na qual ela está empregada - mas pode gerar também uma dependência e certa submissão à atividade laboral, executada primordialmente pelo ganho financeiro vinculado. E como desdobramento, pode-se presumir que a mulher tema lançar-se na busca por novas oportunidades e experiências profissionais que lhe permitiriam maior satisfação e crescimento pessoal e profissional, por receio de perder a estabilidade adquirida e, com isso, a segurança no atendimento das necessidades de seus filhos. Tende-se assumir menos riscos. E caso os ganhos financeiros passem a ser o único, ou o principal fim da sua atividade laboral, esta pode lhe causar sofrimentos futuros, uma vez que o sentido atribuído ao trabalho não decorre mais da função social dele.

A ocasião do nascimento de um bebê necessariamente impõe à família um período de adaptação frente às novas demanda. Como já discutido, muitas vezes as mães são as principais responsáveis pelo cuidado para com a criança, dedicando em tempo integral para atender as suas necessidades. Comumente, nas semanas que antecedem o parto e algum tempo depois deles, as mães entram em um estado particular, denominado de "preocupação materna primária”, por Winnicott (1978). Este estado é natural e necessário, e caracteriza-se por uma sensibilidade aumentada, que possibilita às mães conectarem-se às necessidades de seu bebê, afastando-se temporariamente de seus demais interesses. Este fenômeno é intenso e dura algumas semanas, tende a ir enfraquecendo com o passar do tempo e normalmente as mulheres não o percebem e nem se recordam dele. E quando normalmente já se encontram organizadas após a chegada do bebê, o retorno ao trabalho exige um novo esforço adaptativo das mulheres, que envolve o afastamento da unidade mãe e filho, a terceirização do cuidado com o bebê e uma nova fonte que demanda exigência e dedicação. Parte das entrevistadas, quatro delas, afirmaram que ainda estão em adaptação a este novo momento de vida, conciliando maternidade e o trabalho. É natural que exista a necessidade de adaptação no momento da chegada de um novo membro da família, principalmen- 
te de um bebê que exige cuidados e dedicação. Esta é a primeira grande adaptação na situação do nascimento do primeiro filho e do retorno ao trabalho. No entanto, as mulheres demonstram que para retornar ao trabalho após o nascimento, é necessário um novo esforço de adaptação, que tende a ser tão intenso quanto o primeiro - o momento do nascimento do bebê, e algumas vezes acaba trazendo sofrimento. Cláudia destaca a sua dificuldade de deixar seu filho na escola para retornar ao trabalho:

Ele se adaptou super bem, mas eu acho que a pior parte foi a minha adaptação para deixá-lo. Mas eu chorei. Daí eu fiz toda essa adaptação, e pensei que quando eu começasse a trabalhar daria tudo certo. Mentira. Veio tudo novamente, a sensação daqueles primeiros dias de adaptação, o choro, a insegurança de deixá-lo.

O trabalho de Krause (2017) evidenciou sentimentos negativos em $70 \%$ da amostra de mulheres que retornaram ao trabalho após a licença maternidade, tais como: angústia medo, insegurança e tristeza. A fala de Eduarda denota seus sentimentos:

Estava bem certa que voltaria a trabalhar depois da licença, de que eu seria uma mãe muito tranquila, que quando desse os 4 meses eu estaria louca para voltar a trabalhar. Mas depois que ele nasceu eu queria a qualquer custo não voltar mais a trabalhar. Esse assunto me desesperava, olha posso dizer que sofri um pouco, deu tristeza. Eu não queria mais voltar, tinha medo de como ia ser.

Assim, a fim de garantir a saúde emocional de mulheres e suas famílias, todos os agentes sociais envolvidos - como as empresas e a rede de apoio da família - devem levar em conta que o momento de retorno ao trabalho exige tal adaptação, a fim de proporcionar recursos que permitam à mulher vivenciá-lo de maneira mais funcional possível.

Fabbro e Heloani (2010) afirmam que a maternidade continua sendo uma experiência importante para as mulheres, que proporciona um sentimento de reconhecimento social, valorização e realização pessoal, embora não com a mesma intensidade de outrora. A fala de todas as participantes mostrou explicitamente o quanto a experiência da maternidade foi significativa para elas. Para Alice: "É tu conhecer o amor de verdade. É um amor incondicional, indescritível"; Para Beatriz: "É inexplicável, não tem explicação o que é ter um filho. É como dizem, só quem tem um filho sabe descrever o que é o amor de verdade. [...] É muito amor, é uma coisa muito grande o que tu sente por um filho"; Para Cláudia: "O amor de mãe é demais. É mega protetor. É um amor puro, de troca, de cumplicidade. Muita sincronia. Muito gostoso"; Para Daniele: "É um amor que eu nunca imaginei que iria sentir, é incondicional"; Para Eduarda: "É tudo, é um amor incondicional, é uma extensão de ti, é uma alegria, um amor incondicional. [...] É tu tirar teu coração e dar pra ele se for preciso. É tirar a tua vida e dar. Não tem como descrever"; Para Flávia: "Ela pra mim é um milagre, e é a filha que eu tanto queria. É o amor da minha vida".

Quando uma mulher opta por vivenciar este importante papel concomitantemente ao papel profissional, de fato precisará equilibrar todas as demandas deles advin- dos, já que retorno ao trabalho após a licença maternidade imputa à mulher uma diversidade de mudanças e, com estas mudanças, novas adaptações. Schlickmann (2010) em sua pesquisa identificou que mulheres que exercem trabalho remunerado sentem dificuldade para conciliar os múltiplos papéis exercidos por elas após a maternidade, entre eles o profissional. Spindola e Santos (2004) vão além, mencionando que a relação mãe-filho-trabalho implica necessariamente que a mulher vivencie a situação ambígua de ser trabalhadora e mãe, não somente logo após seu retorno ao trabalho, mas a longo prazo, enquanto tiver que conciliar os dois contextos e tentar atender tantas solicitações e exigências diferenciadas. Krause (2017) afirma que as participantes de seu estudo se sentiam cansadas $(87,5 \%)$, sobrecarregadas $(79,2 \%)$, com pouco tempo $(85,4 \%)$ e sempre ou frequentemente pensavam em desistir do trabalho para ficar somente cuidando do bebê $(49,2 \%)$, e apesar disso, seguiam trabalhando, assim como as participantes do presente estudo. O que estaria por detrás da escolha de permanecer no mercado de trabalho após a maternidade?

A partir da fala de todas as seis participantes, foi possível identificar que o retorno ao trabalho foi motivado por ganhos particulares que o trabalho é capaz de proporcionar, além do financeiro, apesar de elas mencionarem que os ganhos financeiros adquirem importância maior após a maternidade. Ainda assim, as mulheres que retornam ao trabalho após a maternidade, o fizeram também por conta das vantagens que o trabalho pode agregar ao ser humano como a valorização pessoal, a identificação e significação com as atividades realizadas e relacionamentos sociais proporcionados pelo trabalho exercido, apesar de nem sempre esses aspectos estarem explícitos e claros no discurso verbal delas como a questão financeira esteve. Uma das vantagens de terem retornado ao trabalho, presente na fala de todas as mulheres entrevistadas, foi o sentimento de "utilidade" que o trabalho é capaz de lhes proporcionar, onde elas puderam voltar a exercer outros papéis e atividades que não somente os maternos e domésticos, conforme a fala de Cláudia:

Eu me sinto no mercado de trabalho. Eu tinha muito medo de parar e ficar bitolada, estagnada. Eu me sinto viva, sabe? Eu não tenho só o papel de mãe, eu não quero só o papel de mãe. Então uma vantagem é essa, é o raciocínio, ter os teus colegas de trabalho, e dai tu não ficar bitolada.

Em segundo lugar, evidenciou-se na fala de cinco mulheres, que o retorno ao trabalho também lhes proporcionou a oportunidade de estabelecerem relacionamentos interpessoais que vão além do âmbito familiar, conforme a fala de Eduarda: "O convívio com as pessoas também é uma vantagem, porque em casa tu fica muito antissocial, tu não sabe mais o que é mundo". Para Beatriz: "Vantagem é que a gente tem um pouco mais de liberdade, tu tem com quem rir, com quem, conversar [...] tu tá com os teus amigos, num ambiente que tu se sente bem, tu se distrai, o teu dia passa com mais clareza". 
E somente em terceiro lugar, o retorno ao trabalho foi creditado à manutenção dos ganhos financeiros, mencionado por quatro entrevistadas, conforme afirma Flávia: "A maior vantagem é tu ter o teu dinheirinho a mais né? Tu é independente, até pra comprar as tuas coisinhas, as coisas pra ela. Tu não precisa ficar dependendo dele, pedindo pra ele [esposo]".

A partir do relato das seis mulheres participantes deste estudo, confirmou-se que o trabalho é um importante constituidor da sua subjetividade e individualidade, considerado como um importante papel desempenhado por elas que agrega sentimento de valorização e reconhecimento social. As mulheres que retornam ao trabalho após a licença maternidade perceberam três principais vantagens no retorno ao trabalho, que foi a) a valorização pessoal, a identificação, o prazer; b) a significação que extraem da atividade desempenhada e; c) os relacionamentos propiciados pelo trabalho exercido. Aspectos, esses que também estão relacionados aos onze benefícios psicossociais que o trabalho é capaz de proporcionar aos sujeitos, arrolados por Salanova, Gracia e Peiró (1996 apud SANTOS, 2006). Entende-se que o retorno ao trabalho após a licença maternidade foi motivado por estes fatores pessoais, pelo sentimento de estarem atuantes, produtivas, ampliando seus papéis sociais para além dos papéis de mãe e de dona de casa, apesar da ambivalência de sentimentos produzidos por esse retorno. Com isso, as participantes viabilizam a possibilidade continuar explorando novos contextos e estabelecer relacionamentos pessoais não restritos à casa e à família. Ainda assim, a experiência materna foi desejada e continua sendo valorizada pelas mulheres parecendo ser, a partir das falas das participantes, uma experiência significativa e recompensadora para elas e que alterou o significado atribuído por elas ao trabalho.

\section{Considerações finais}

Com o objetivo de caracterizar a relação de mulheres com o seu trabalho, após a experiência da maternidade, identificando as implicações que o nascimento do primeiro filho e a retomada das atividades laborais podem exercer na rotina e no trabalho da mulher, foi possível verificar que a rotina das mulheres muda com a chegada da criança e o retorno ao trabalho, e a principal implicação desta mudança expressa-se pelo cansaço físico advindo da realização das diversas funções que os múltiplos papéis desempenhados exigem da mulher. Com o retorno ao trabalho as mulheres relatam ainda que o sentimento de preocupação é ressaltado, interferindo no seu desempenho satisfatório de outros papéis que não o materno, fazendo com que elas desejem conseguir preocupar-se menos com a criança e destinar sua atenção às demais atividades. Com isso, o próprio significado do trabalho é modificado para as mulheres que vivenciam a maternidade.

A partir do relato das entrevistadas, confirmou-se a importância do trabalho na constituição da subjetividade e individualidade dos sujeitos. Os benefícios sociais, cognitivos e emocionais por ele viabilizado estimulam as trabalhadoras mães a enfrentar as dificuldades a fim de equilibrar dois papéis tão distintos que exigem dedicação intensa. O retorno ao trabalho após a licença maternidade permite que as mulheres sintam-se atuantes, produtivas e em movimento, ampliando seus papéis sociais para além dos papéis de mãe, esposa e cuidadora da casa. Com isso, as mulheres trabalhadoras viabilizam explorar o desenvolvimento de competências profissionais, usufruem de reconhecimento social, estabelecem relacionamentos pessoais não restritos à casa e à família, além de alcançar remuneração financeira. A experiência materna foi desejada e continua sendo valorizada pelas mulheres participantes, parecendo ser uma experiência bastante significativa e recompensadora para elas. Desta forma, pode-se dizer que é possível conciliar estes dois papéis de maneira saudável, desde que a mulher, sua família e a organização em que atua tenham clareza da necessidade de adaptação às novas demandas que irão surgir e dos obstáculos que a mulher precisará superar.

Os resultados identificados encontram algumas restrições e apontam para novos estudos, uma vez que a amostra foi pequena e composta exclusivamente de mulheres com união estável, empregadas no setor privado com carga horária integral, mães do primeiro filho e que tiveram a gravidez planejada. Uma amostra heterogênea pode apresentar resultados diversos. Além disso, abordou-se exclusivamente a percepção da mulher em relação à sua rotina e trabalho. Assim, sugere-se a necessidade de novos estudos na área que tragam uma percepção mais ampla e generalista da temática abordada.

Destaca-se o papel do psicólogo como orientador neste momento de transição, capaz de auxiliar a mulher a identificar as necessidades existentes em seu dia a dia, repensar suas escolhas e atuações, bem como identificar em sua rede de apoio as possibilidades que permitirão vivenciar um retorno ao trabalho e uma adaptação à nova realidade de forma mais funcional. Destaca-se ainda, a atuação dos psicólogos atuantes com gestão de pessoas, que podem buscar sensibilizar os gestores para que estejam preparados ao vivenciar situação semelhante em sua equipe, mediando situações de conflito. Ações como orientar as mulheres que planejam a maternidade, e as mulheres que retornam desta experiência, podem favorecer que consigam essas mulheres (agora mães) consigam vivenciar a relação de trabalho e maternidade de maneira mais adaptada e menos angustiante. Além disso, os profissionais envolvidos devem permanecer atentos à saúde da mulher que retorna da licença maternidade, acompanhando sua reinserção nas atividades e equipe de trabalho, para que aconteça da forma mais tranquila possível. Possibilidades são inúmeras.

Dificuldades sempre existirão, pois é inerente à vida humana. Contudo, é possível às mulheres encontrarem novos arranjos nas suas vidas após o nascimento do bebê e o retorno ao trabalho, estabelecendo limites entre o que a satisfará ou não, entre o que proporciona prazer e desprazer, num exercício constante, visando ao bem-estar individual, familiar e profissional. E esse se torna um desafio constante às trabalhadoras que se tornam mães e àqueles que gerem o trabalho dessas mães trabalhadoras. 


\section{Referências}

ALVES, J. E. D. Inserção social e exclusão política das mulheres brasileiras. APARTE-Inclusão Social em Debate, Rio de Janeiro, p. 1-15, 2009. Disponível em: http://www.ie.ufrj. br/aparte/pdfs/insercao_social_e_exclusao_politica_das_ mulheres jul09.pdf. Acesso em: 22 ago. 2015.

ANDRADE, T. Mulheres no mercado de trabalho: onde nasce a desigualdade? Brasília: Câmara dos Deputados, 2016. Disponível em: http://www2.camara.leg.br/a-camara/ documentos-e-pesquisa/estudos-e-notas-tecnicas/areas-daconle/tema7/2016 12416 mulheres-no-mercado-de-trabalho tania-andrade. Acesso em: 25 jan. 2018.

BARDIN, L. Análise de conteúdo. São Paulo: Edições 70, 2011.

BRASIL. Presidência da República. Casa Civil. Subchefia para Assuntos Jurídicos. Decreto-Lei $n .^{\circ} 5.452$, de $1^{\circ}$ de maio de 1943. Aprova a Consolidação das Leis do Trabalho. Disponível em: http://www.planalto.gov.br/ccivil_03/decreto-lei/Del5452. htm. Acesso em: 15 jun. 2014.

BRASIL. Ministério de Estado do Trabalho. Portaria $n^{\circ} 3.296$, de 03 de Setembro de 1986. Autoriza as empresas e empregadoras a adotar o sistema de Reembolso-Creche, em substituição à exigência contida no $\S 1^{\circ}$ do art. 389 da CLT. Disponível em: http://www.camara.gov.br/sileg/integras/1174722.pdf. Acesso em: 15 jun. 2014

CAVALCANTI, N. C. S. B., BAÍA, D. C. P. Ser mãe no mundo do trabalho: notas sobre os desafios da reinserção de mulheres no mercado de trabalho após a experiência de maternidade. In: SEMINÁRIO INTERNACIONAL FAZENDO GÊNERO, 11. 2017, Florianópolis; WOMEN'S WORLDS CONGRESS, 13. 2017, Florianópolis. 2017. Anais eletrônicos... Florianópolis: UFSC, 2017. Disponível em: http://www.en.wwc2017.eventos. dype.com.br/resources/anais/1499457316 ARQUIVO Sermaenomundodotrabalho.pdf. Acesso em: 20 dez. 2017.

CHARRAZ, A. S. P. Conciliação entre o trabalho e a família: identificação das práticas organizacionais vigentes e contributos para a implementação de novas práticas de conciliação. 2017. Dissertação (Mestrado em Psicologia)-Escola de Ciências Sociais - Universidade de Évora, Évora, 2017. Disponível em https://dspace.uevora.pt/rdpc/bitstream/10174/20913/1/ Disserta $\%$ C3\%A7\%C3\%A30\%20vers $\%$ C3\%A30\%20SAC Ana\%20Charraz.pdf. Acesso em: 15 maio 2018.

CODO, W. Por uma Psicologia de Trabalho: um diagnóstico do trabalho em busca do prazer. São Paulo: Casa Psi, 2006.

FABBRO, M. R. C.; HELOANI, J. R. M. Mulher, maternidade e trabalho acadêmico. Investigación y Educación en Enfermería Medellín, v. 28, n. 2, p. 176-186, jul. 2010. Disponível em: $\quad$ http://www.scielo.org.co/scielo.php?script=sci arttext\&pid=S0120-53072010000200004. Acesso em: 18 ago. 2015.

GUIMARÃES, J. R. S. (Org.). Perfil do trabalho decente no Brasil: um olhar sobre as unidades da Federação durante a segunda metade da década de 2000. Brasilia: OIT, 2012.

GODOY, M. B. et al. Situação trabalhista da mulher no ciclo grávido-puerperal. Investigación y Educación en Enfermería Medellín, v. 29, n. 1, p. 47-53, mar. 2011. Disponível em: http:/ www.scielo.org.co/scielo.php?script=sci arttext\&pid=S0120$53072011000100006 \& \operatorname{lng}=\mathrm{en} \& n r m=i s o \& \operatorname{lng}=$ pt. Acesso em: 20 ago. 2015
HARRIS, B. Careers, conflict, and children: the legacy of the cult of domesticity. In: ROLAND, A.; HARRIS, B. (Ed.). Career and motherhood: struggles for a new identity. Nova York: Human Sciences Press, 1979. p. 55-86.

HOFFNUNG, M. What's mother to do? Conversations on work and family. Pasadena, Cal: Trilogy Books, 1992.

HOFFNUNG, M. Motherwood: contemporary conflict for women. In: FREEMAN, Jo (Ed.). Women: a feminist perspective. Mountain View, Cal: Mayfield, 1995. p. 83110.

JABLONSKI, B. A divisão de tarefas domésticas entre homens e mulheres no cotidiano do casamento. Psicologia: Ciência e Profissão, Brasília, v. 30, n. 2, p. 262- 275, 2010. Cross ${ }^{R e f .}$

JABLONSKI, B. Afinal, o que quer um casal? Algumas considerações sobre o casamento e a separação na classe média carioca. In. FÉRES-CARNEIRO, T. (Ed.). Família e casal: arranjos e demandas contemporâneas. Rio de Janeiro: Loyolla, 2003. p. $141-168$

JIMENEZ, A. L. et al. Prevenção de doenças sexualmente transmissíveis em mulheres: associação com variáveis sócioeconômicas e demográficas. Cad. Saúde Pública, Rio de Janeiro, v. 17, n. 1, p. 55-62, jan./fev. 2001. Cross ${ }^{\text {Ref. }}$

KRAUSE, L. I. Mulher, trabalho e maternidade: demandas no retorno da licença-maternidade. 2017. Dissertação (Mestrado Profissional em Saude da Mulher, Crianca e Adolescente) Universidade Católica de Pelotas, Programa de Pós-Graduação em Saúde e Comportamento, Pelotas, 2017. Disponível em: http://tede.ucpel.edu.br:8080/jspui/handle/tede/635. Acesso em: 22 ago. 2015.

LINDO, M. R. et al. Vida pessoal e vida profissional: os desafios de equilíbrio para mulheres empreendedoras do Rio de Janeiro. RAC-Eletrônica, Rio de Janeiro, v. 1, n. 1, p. 2-15, jan./ abr. 2007. Disponível em: http://www.anpad.org.br/periodicos/ arq pdf/a 621.pdf. Acesso em: 25 ago. 2015.

NASCIMENTO, G. A. F.; VILLAS BÔAS, R. V. Proteção da mulher: direito individual e social à igualdade de condições no mercado de trabalho e ao direito à maternidade. Conpendi Law Review, v. 1, n. 6 (III Encontro de Internacionalização do CONPENDI - Madrid), p. 156-172, 2015. Disponível em: http://www.indexlaw.org/index.php/conpedireview/article/ view/3459/2972. Acesso em: 28 jul. 2015.

ORGANIZAÇÃO INTERNACIONAL DO TRABALHO. BRASIL. Igualdade de gênero e raça no trabalho: avanços e desafios. Brasília: OIT, 2010

ORGANIZAÇÃO INTERNACIONAL DO TRABALHO. Mulheres no Trabalho: tendências 2016. Genebra: OIT, 2016.

RAPOPORT, A; PICCININI, C. A. Apoio social e experiência da maternidade. Revista Brasileira de Crescimento e Desenvolvimento Humano, São Paulo, v. 16, n. 1, p. 8596, 2006. Disponível em: http://pepsic.bvsalud.org/scielo. php? script=sci_arttext\&pid=S0104-12822006000100009. Acesso em: 30 jul. 2015.

RODRIGUES, C. SAPUCAIA, M. Proteção à maternidade: uma reflexão sobre apaziguamento e sedimentação das desigualdades entre homens e mulheres. Revista da ABET, Curitiba, v. 15, n. 1, p. 22-32, jan./jun. 2016. Disponível em: http://www.periodicos.ufpb.br/index.php/abet/article/ view/31257/16335. Acesso em: 15 jul. 2015. 
ROCHA-COUTINHO. Dos contos de fadas aos super-heróis: mulheres e homens brasileiros reconfiguram identidades. Psicologia Clínica, v. 12, n. 2, p. 65-82, 2001.

ROCHA-COUTINHO. Quando o executivo é uma "dama": a mulher, a carreira e as relações familiares. In: FÉRESCARNEIRO, T. (Org.). Família e casal: arranjos e demandas contemporâneas. Rio de Janeiro: PUC-Rio, 2003a. p. 57-77.

ROCHA-COUTINHO. Divididas e multiplicadas: a maternidade para mulheres executivas cariocas. In: D'ÁVILA NETO, M. I.; PEDRO, R. (Org.). Tecendo o desenvolvimento: saberes, gênero, ecologia social. Rio de Janeiro: Mauad/Bapera, 2003b. p.107-125.

ROCHA-COUTINHO, M. L. Variações sobre um antigo tema: maternidade para mulheres. In: FÉRES-CARNEIRO, T. (Org.). Família e casal: efeitos da contemporaneidade. Rio de Janeiro: PUC, 2005. p. 122-137.

SANTOS, C. A. Significado do trabalho e conduta éticoprofissional: um estudo de caso na Polícia Militar baiana. 2006. 146 f. Dissertação (Mestrado)-Núcleo de Pós-Graduação em Administração - NPGA, Universidade Federal da Bahia, Salvador, 2006

SCHLICKMANN, D. B. Mulher, trabalho e maternidade: como fica a carreira após a chegada dos filhos? Trabalho de Conclusão de Curso (Graduação em Psicologia)-Universidade do Sul de Santa Catarina, Palhoça, 2010.

SPINDOLA, T.; SANTOS, R. Trabalho versus vida em família: conflito e culpa no cotidiano das trabalhadoras de enfermagem. Cienc. enferm., Concepción, v. 10, n. 2, p. 43-52, dez. 2004. Cross ${ }^{\text {Ref. }}$

VANALLI, A. C. G.; BARHAM, E. J. Após a licençamaternidade: a percepção de professoras sobre a divisão das demandas familiares. Psicologia \& Sociedade, Belo Horizonte, v. 24, n. 1, p. 130-138, jan./abr. 2012. Cross ${ }^{\text {Ref. }}$

VINHAS, A. P. B. L. Mitos da maternidade: um estudo a partir do olhar sistêmico. 2009, 40 f. Monografia (Especialização em Teoria Relacional Sistêmica). Familiare Instituto Sistêmico, Florianópolis, 2009.

WINNICOTT, D. Preocupação materna primária. In: Textos selecionados: da pediatria à psicanálise. Rio de Janeiro: Francisco Alves, 1978. p. 491-498.

Recebido em: 17 de setembro de 2015 Aceito em: 27 de fevereiro de 2018 